\title{
ASO Visual Abstract: Ratio of Pathological Response to Preoperative Chemotherapy in Patients Undergoing Complete Cytoreduction and Hyperthermic Intraperitoneal Chemotherapy for Metastatic Colorectal Cancer Correlates with Survival
}

Eyal Mor, MD ${ }^{1}$ (i) , Dan Assaf, MD ${ }^{1}$, Shachar Laks, MD ${ }^{1}$, Haggai Benvenisti, MD ${ }^{1}$, Gal Schtrechman, MSc ${ }^{1}$, David Hazzan, MD ${ }^{1}$, Lior Segev, MD ${ }^{1}$, Ronel Yaka, MD ${ }^{1}$, Einat Shacham-Shmueli, MD $^{2}$, Ofer Margalit, $\mathrm{MD}^{2}$, Naama Halpern, $\mathrm{MD}^{2}$, Daria Perelson, $\mathrm{MD}^{3}$, Monica-Inda Kaufmann, $\mathrm{MD}^{4}$, Almog Ben-Yaacov, MD ${ }^{1}$, Aviram Nissan, MD $^{1}$, and Mohammad Adileh, MD $^{1}$

${ }^{1}$ The Department of General and Oncological Surgery - Surgery C Sheba Medical Center, Tel Hashomer, Affiliated with the Sackler School of Medicine, Tel Aviv University, Tel Aviv, Israel; ${ }^{2}$ The Department of Oncology, Sheba Medical Center, Tel Hashomer, Affiliated with the Sackler School of Medicine, Tel Aviv University, Tel Aviv, Israel; ${ }^{3}$ The Department of Anesthesiology, Sheba Medical Center, Tel Hashomer, Affiliated with the Sackler School of Medicine, Tel Aviv University, Tel Aviv, Israel; ${ }^{4}$ The Department of Phatology, Sheba Medical Center, Tel Hashomer, Affiliated with the Sackler School of Medicine, Tel Aviv University, Tel Aviv, Israel

Pathological response ratio to systemic therapy following cytoreductive surgery (CRS) and hyperthermic intraperitoneal chemotherapy (HIPEC) correlates with survival. Our study supports utilization of preoperative therapy for better patient selection with potential impact on survival (https://doi.org/10.1245/s10434-021-10367-6).

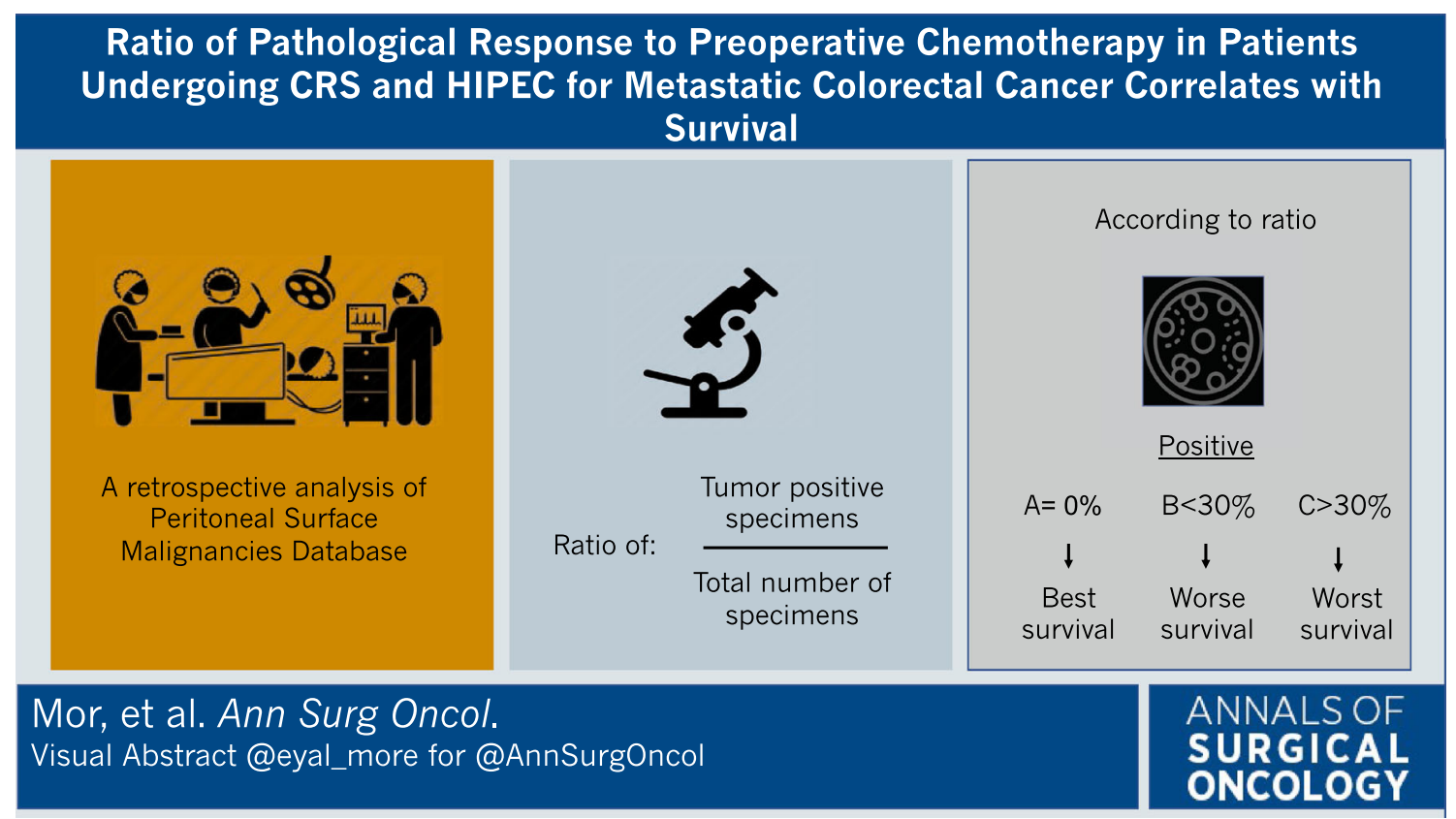

(C) Society of Surgical Oncology 2021

Published Online: 20 July 2021

M. Adileh, MD

e-mail: Mohammad.Adileh@sheba.health.gov.il
DISCLOSURE The authors report no conflicts of interests.

Publisher's Note Springer Nature remains neutral with regard to jurisdictional claims in published maps and institutional affiliations. 